\title{
Numerical modelling of temperature fields in the flow boiling liquid through a vertical minichannel with an enhanced heating surface
}

\author{
Sylwia Hożejowska ${ }^{1, a}$, Magdalena Piasecka ${ }^{1}$ \\ ${ }^{1}$ Kielce University of Technology, Al. 1000-lecia PP 7, 25-314 Kielce Poland
}

\begin{abstract}
The paper presents results of heat transfer research on flow boiling in a rectangular minichannel positioned vertically, with an enhanced surface. One of the channel walls was made of thin foil powered by direct current. This foil is enhanced on the side contacting fluid in the minichannel. It is possible to observe both surfaces of the minichannel through two openings covered with glass panes. One allows detecting temperature of the plain side of the foil by liquid crystal thermography. The opposite surface of the minichannel (from the enhanced side of the foil) can be observed through the other glass pane. The observations of the flow structures allowed to calculate the void fraction for some cross-sections of selected two phase flow images. In mathematical modelling of the considered process stationary heat transfer in a glass pane, heating foil and boiling liquid can be described with Laplace equation, Poisson equation and energy equation, respectively. For completeness of the model a corresponding system of boundary conditions was given. The two-dimensional temperature fields of glass pane, heating foil and fluid was computed with the Trefftz method. The equalizing calculus used to smooth the measured data has reduced errors.
\end{abstract}

\section{Introduction}

Over recent years, the range of applications for the flow boiling heat transfer through minichannels with different geometries has been widened considerably, extending over a new generation of cooling systems, compact heat exchangers, electrical devices, etc. Extensive efforts have been aimed at understanding boiling phenomena in miniand microchannels. They include theoretical analyses and models, experimental measurements and observations, empirical correlations, etc. The results of experimental research provide design information for cooling systems furnished with minichannel devices and can be applied in cooling, thermostabilization and thermoregulation of devices high heat flux. Numerous issues related to minichannel systems heated by smooth heaters have been already verified experimentally. The application of enhanced surfaces in boiling heat transfer in narrow channels has not been studied sufficiently. The studies concentrating on enhanced structure systems attract attention due to their use in their theoretical enhancement potential for heat transfer.

Review of relevant literature and the selected publications covering flow boiling heat transfer in minichannels is presented in [1-3], and in addition, having enhanced surfaces - in $[4,5]$.

\footnotetext{
${ }^{\mathrm{a}}$ Corresponding author: ztpsf@tu.kielce.pl
}

\section{Experimental stand}

\subsection{The test section and main experimental issues}

The essential part of the experimental stand is the test section with a rectangular, $1 \mathrm{~mm}$ deep, $40 \mathrm{~mm}$ wide, and $360 \mathrm{~mm}$ long minichannel vertically positioned (figure $1 \mathrm{a}, \# 1)$. The heating element for the working fluid which flows along the minichannel is $0.1 \mathrm{~mm}$ alloy foil (\#2) made from Haynes-230. It is powered by an inverter welder as a regulated current DC power supply. The experiment has been carried out with FC-72 at mass flux $212 \mathrm{~kg} /\left(\mathrm{m}^{2} \mathrm{~s}\right)$, Reynolds number about 660 and inlet pressure $126 \mathrm{kPa}$. The heating foil is enhanced on the side of the fluid flowing in the minichannel (\#5). It is possible to observe both surfaces of the minichannel through two openings covered with glass sheets (\#4). One of them allows observing changes in the colour of the plain foil surface through the glass $(\# 4 b)$. This side of the heating foil is covered with a base coat and liquid crystal paint. Application of the liquid crystal thermography for the detection of two-dimensional heating surface temperature distribution must be preceded using colour (hue); and temperature calibration is required. In the calibration experiment of the colour vs. 
temperature of the liquid crystals covered surface, it is the colour image that provides the basis for the determination of the two-dimensional surface temperature distribution $[6,8]$. Heating foil temperature dependence along the distance from the minichannel inlet is presented in figure $2 \mathrm{~b}$. This data derived from the images shown in figure $2 \mathrm{a}$, and was constructed on the basis of the central part of the foil along the distance from the channel. The opposite surface of the minichannel (from the enhanced side of the foil) can be observed through the other glass pane (figure 1a, \#4a) and allows the identification of the vapour-liquid two-phase flow patterns (shown in figure 1b) and the void fraction calculated on its basis (see figure 4). In order to collect experimental data for further calculations, current supplied the heating foil, voltage drop, volumetric flow rate and pressure in the inlet and outlet to the minichannel were measured. The complete experimental stand was presented in detail in [3-7]. The data and the image acquisition system consist of digital cameras (figure 1a, \#8, \#9), the data acquisition station, a computer with special software and lighting systems.
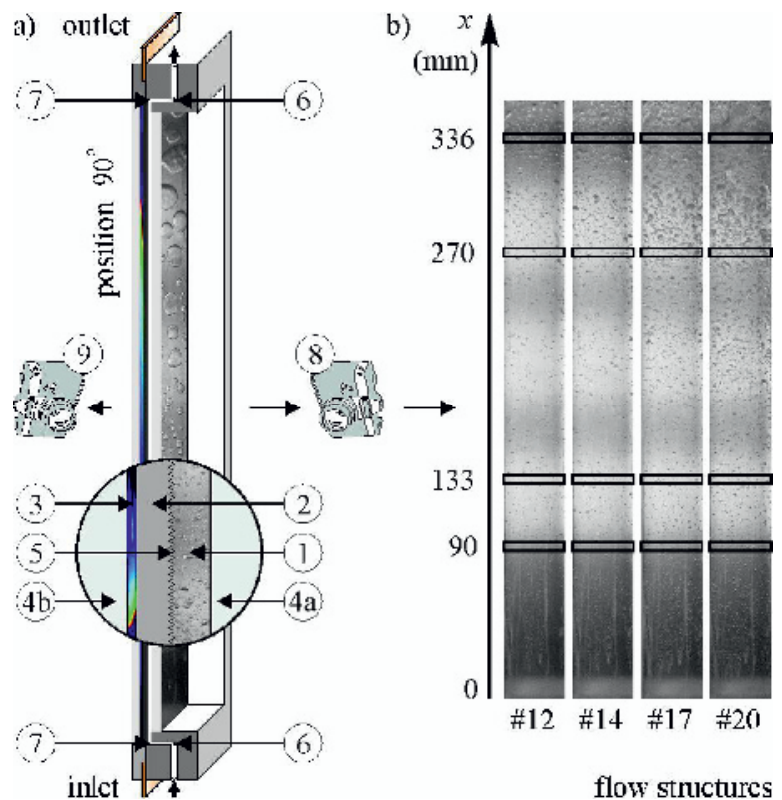

Figure 1. a) The schematic diagrams of the test section positioned vertically, \#1-minichannel, \#2-heating foil, \#3-liquid crystal layer, \#4a,b-glass sheet, \#5-enhanced surface,

\#6-pressure converter, \#7-thermocouple, \#8-digital camera, \#9-digital SLR camera, b) two phase flow images, selected from the discussed series, experimental parameters as for figure 2 .

The enhanced side of the foil consists of the microrecesses evenly distributed (every $100 \mu \mathrm{m}$ in both axes), performed by laser drilling. The diameter of the single micro-recesses is $10 \mu \mathrm{m}$, its depth is $3 \mu \mathrm{m}$. A 5-7 $\mu \mathrm{m}$ high layer of melted metal accumulates annularly around the recesses, forming the structure of "craters", figure 3.
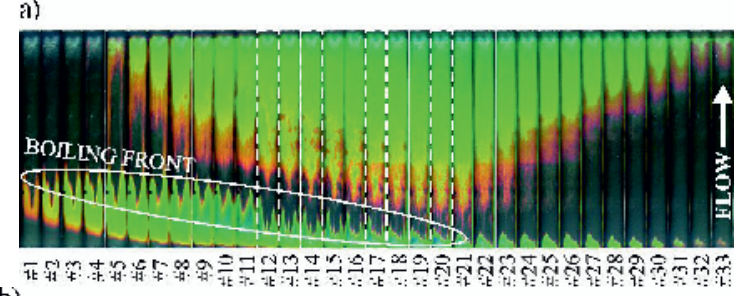

b)
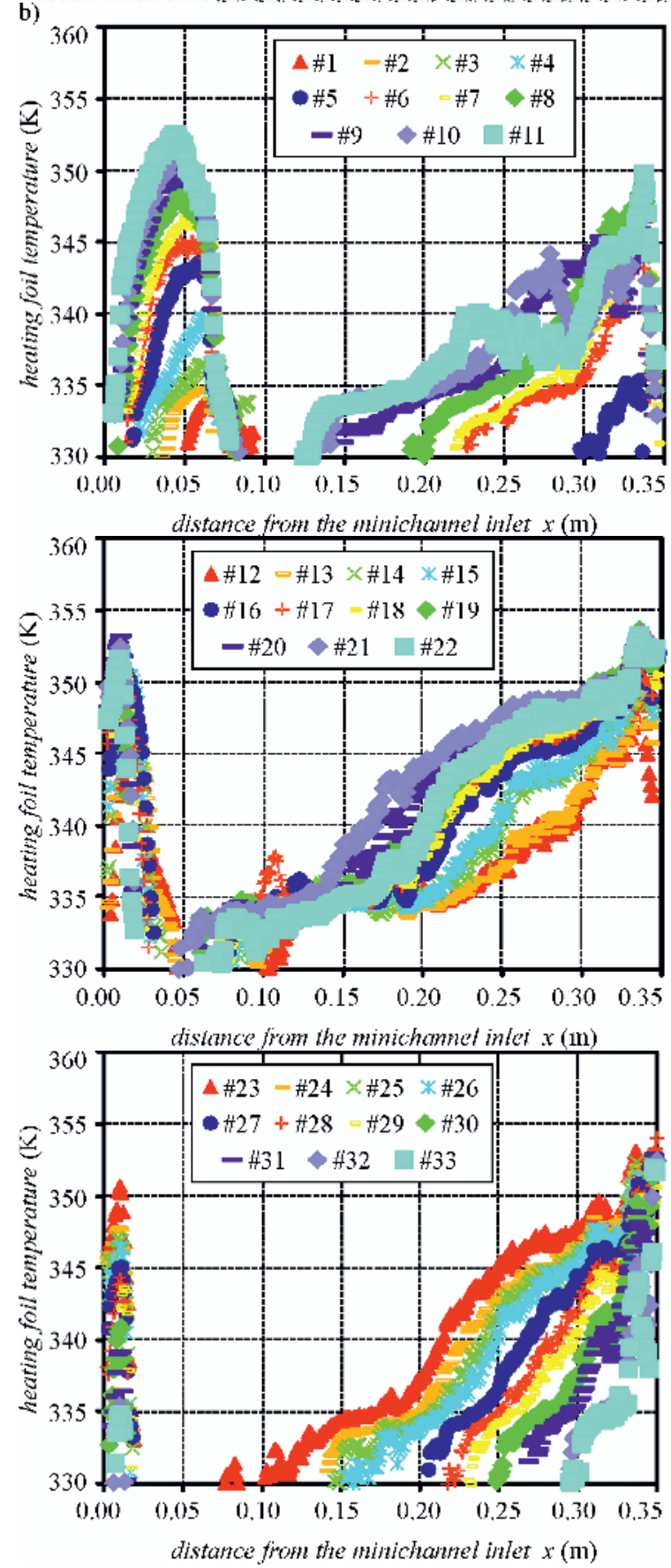

Figure 2. a) Hue distribution on the plain side of the foil, all for the discussed series, b) resultant heating foil temperature dependence on the distance along the minichannel length, experimental parameters: flow velocity $0.12 \mathrm{~m} / \mathrm{s}$, mass flux $212 \mathrm{~kg} /\left(\mathrm{m}^{2} \mathrm{~s}\right)$, pressure at the inlet to the channel $126 \mathrm{kPa}$, inlet liquid subcooling $42 \mathrm{~K}$; volumetric heat flux $q_{v}=9.93 \cdot 10^{4} \div 2.29 \cdot 10^{5} \mathrm{~kW} / \mathrm{m}^{3}$. 


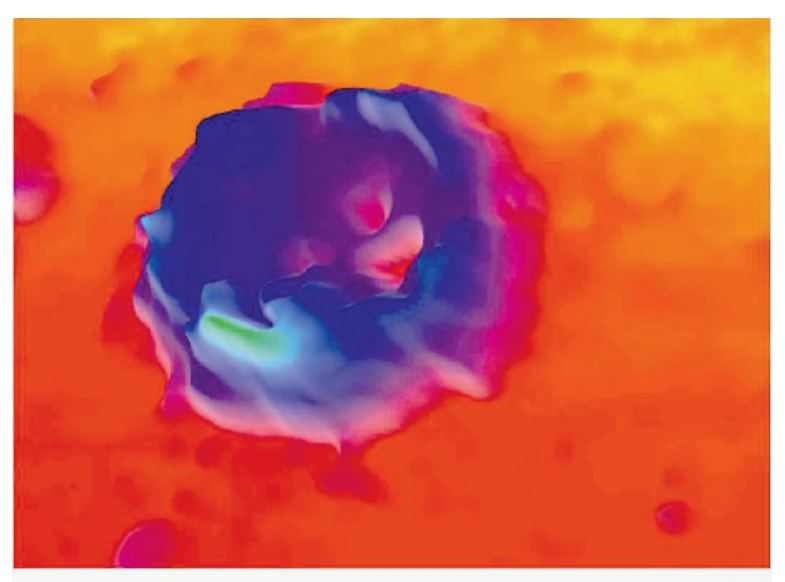

$\mu \mathrm{m}$

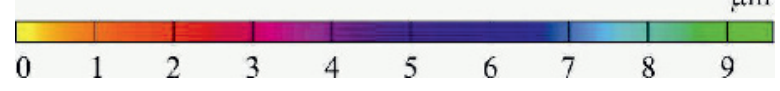

Figure 3. 3D topography of the sampled area of the enhanced foil with micro-recesses.

\subsection{Experimental methodology}

After deaeration the gradual increase in the power supply to the heating foil results in an increased heat flux transferred to the FC-72 flowing in the minichannel (figure 2, settings from \#1 to \#21). This leads to the boiling incipience (recognizable as "boiling front" [1-7]) and next to the development of nucleate boiling. Then power supply to the foil is reduced gradually (settings from \#22 to \#33). Thanks to the liquid crystal layer located on its surface contacting the glass it is possible to measure temperature distribution on the heating wall. Liquid crystal properties and technique is described in detail in [8]. Flow structure is observed at the same time at the opposite side of the minichannel.

The accuracy of heating foil temperature measurements by using liquid crystal thermography and heat source efficiency measurement error in the same research set up were evaluated in $[3,8]$. The mean temperature measurement error of heating foil by liquid crystal thermography was $0.86 \mathrm{~K}$. The relative volumetric heat flux measurement error amounted to $3.53 \%$.

\subsection{Void fraction determination}

Flow structures were analyzed using the monochrome images of flow structures. They were analyzed stereologically, using Techsystem Globe software for quantitative assessment. It led to the determination of the areas of the two phases and/or the percentage of share the defined phase. Four settings (\#12, \#14, \#17 and \#20, see figure $1 \mathrm{~b}$ ) for increasing of heat flux supplied to the heating surface were selected for analysis. In figure 4 selected two phase flow images (a) and cross-sections of real (b) and binarized structure images (c) adopted for analysis in Techsystem Globe. In the case of four crosssections of each image $(5 \times 40 \mathrm{~mm})$, marked in figure $1 \mathrm{~b}$, the void fraction is determined.
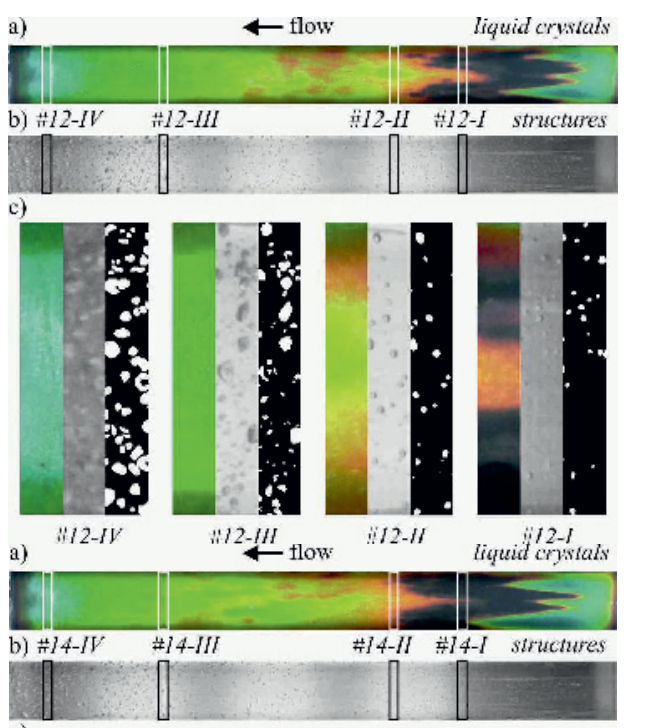

c)
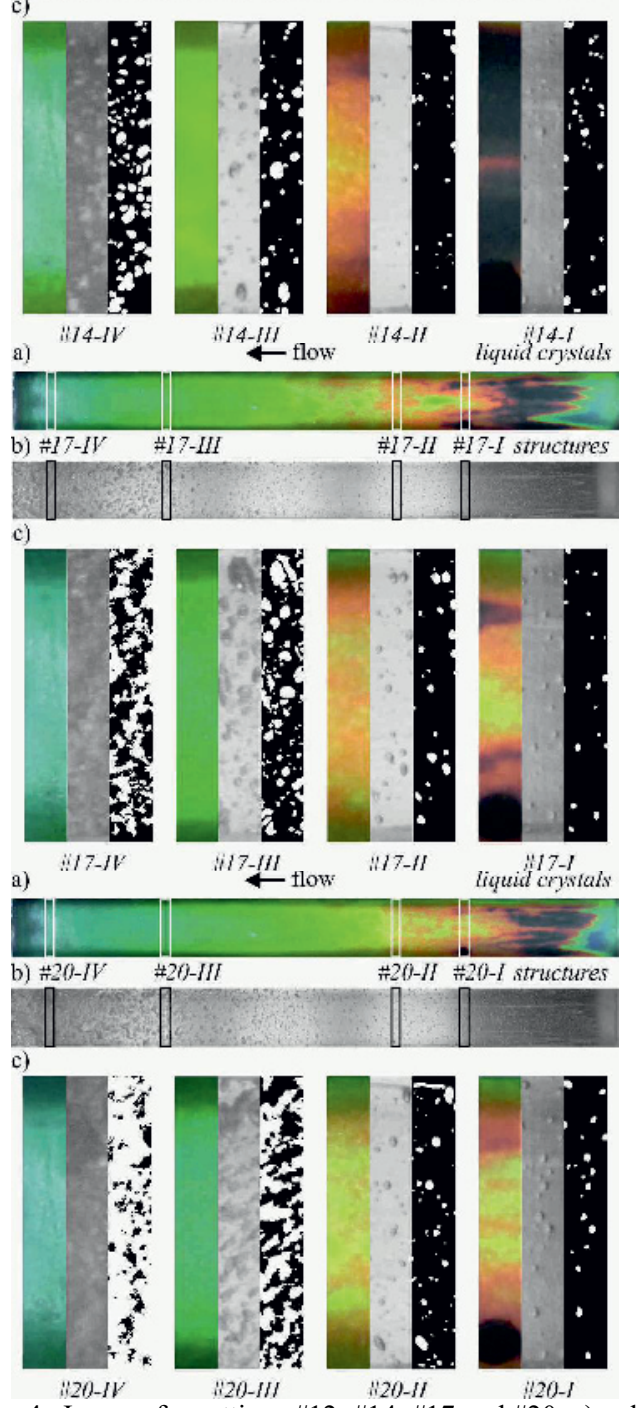

Figure 4. Images for settings \#12,\#14,\#17 and \#20; a) colour heating foil image; b) the corresponding two-phase flow structure image; c) cross-sections of: colour heating foil image, real and binarized two-phase flow structure image; white colour refers to the vapour, and the black colour represents the liquid; parameters as for figure 2 . 
The cross-sectional void fraction $\varphi_{\exp }$ was determined according to the formula:

$$
\varphi_{\exp }=\frac{V_{v}}{V_{l}+V_{v}}=\frac{A_{v} \delta_{M}}{\left(A_{l}+A_{v}\right) \delta_{M}}=\frac{A_{v}}{A_{l}+A_{v}}
$$

where: $V$-volume, $A$-cross section area, $\delta_{M}$-minichannel depth, letters in subscript apply to the following phases: liquid ( $l$ in subscript) or vapour ( $v$ in subscript).

The results are presented in figure 5 as the void fraction dependence along the minichannel length. In evaluation, the absolute error of the void fraction was assumed to be equal to the area (point) comprising 0.0064 $\mathrm{mm}^{2}$; this value was estimated on the basis of the resolution of the picture taken by a digital camera $[6,8]$.

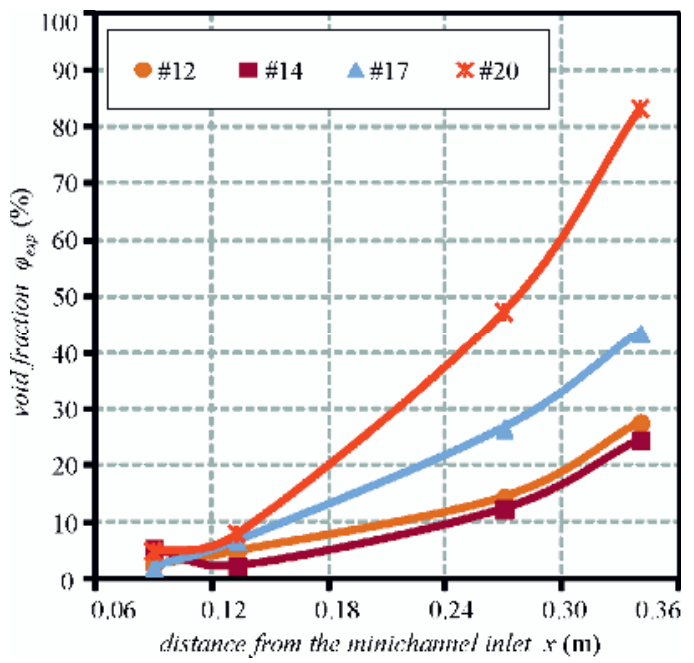

Figure 5. The void fraction dependence along the minichannel length.

\section{Mathematical model}

The mathematical model and all the calculations are restricted to the region located in the central part of the minichannel, assuming that any physical phenomenon occurring at the edges of the module does not influence on thermodynamic parameters of the processes in the region under consideration. To perform mathematical modelling with greater ease, only two dimensions were taken into account: dimension $x$ along the flow direction, and perpendicular to it dimension $y$ relating to the thickness of the glass barrier $\left(\delta_{G}\right)$, the thickness of the foil $\left(\delta_{F}\right)$ and the depth of the minichannel $\left(\delta_{M}\right)$, figure 6 . In further notation the following subscripts are introduced: $G$ for glass barrier, $F$ for heating foil and $f$ for fluid.

It was assumed that the steady state temperature of the glass barrier $T_{G}(x, y)$ satisfies Laplace equation, [1,2]

$$
\nabla^{2} T_{G}=0
$$

supplied with the boundary conditions

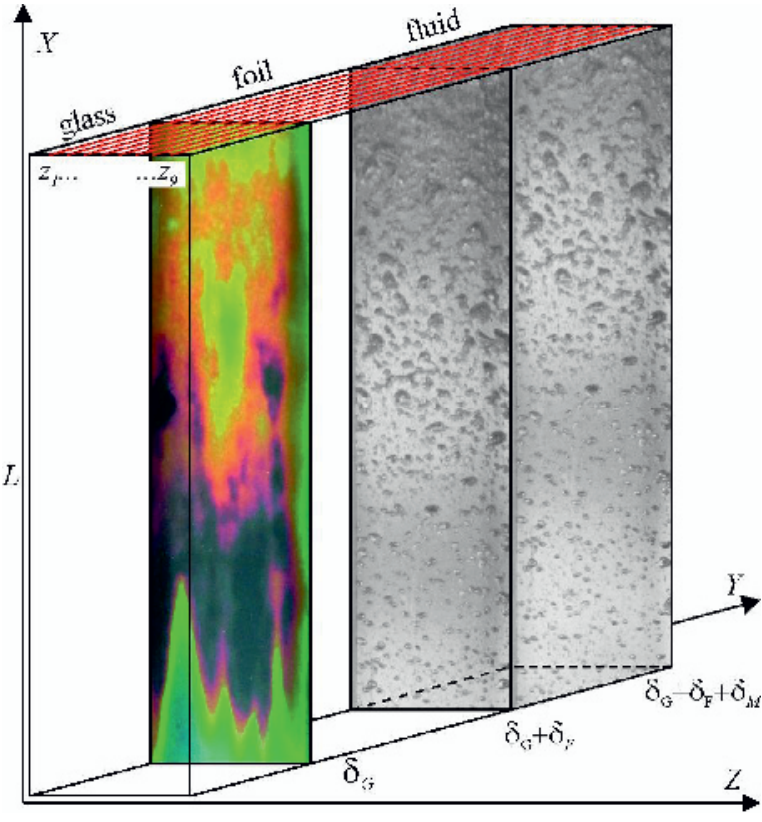

Figure 6. Diagram of the test section with the minichannel. Temperature distribution at the foil-glass interface obtained by the liquid crystals and the flow structure corresponding with the given temperature distribution (pictorial view, not to scale).

$$
\begin{gathered}
T_{G}\left(x_{n}, \delta_{G}\right)=T_{n} \text { for } n=1,2, \ldots, N \\
\frac{\partial T_{G}}{\partial y}=0 \text { for } y=0,0 \leq x \leq L \\
\frac{\partial T_{G}}{\partial x}=0 \text { for } x=0,0 \leq y \leq \delta_{G} \\
\frac{\partial T_{G}}{\partial x}=0 \text { for } x=L, 0 \leq y \leq \delta_{G}
\end{gathered}
$$

where: $\nabla^{2}=\frac{\partial^{2}}{\partial x^{2}}+\frac{\partial^{2}}{\partial y^{2}}, T_{n}$ denotes the temperatures at the glass - heating foil interface at discrete points $\left(x_{n}, \delta_{G}\right), L-$ minichannel length, $N$ - number of measurement points.

The steady state temperature of the heating foil $T_{F}(x, y)$ satisfies Poisson equation, [1,2]

$$
\nabla^{2} T_{F}=-\frac{q_{V}}{\lambda_{F}}
$$

subject to the boundary conditions

$$
\begin{aligned}
& T_{F}\left(x_{n}, \delta_{G}\right)=T_{n} \text { for } n=1,2, \ldots, N \\
& T_{F}\left(x, \delta_{G}\right)=T_{G}\left(x, \delta_{G}\right) \text { for } 0 \leq x \leq L \\
& \frac{\partial T_{F}}{\partial x}=0 \text { for } x=0, \delta_{G} \leq y \leq \delta_{G}+\delta_{F} \\
& \frac{\partial T_{F}}{\partial x}=0 \text { for } x=L, \delta_{G} \leq y \leq \delta_{G}+\delta_{F}
\end{aligned}
$$




$$
\lambda_{F} \frac{\partial T_{F}}{\partial y}=\lambda_{G} \frac{\partial T_{G}}{\partial y} \text { for } y=\delta_{G}, 0 \leq x \leq L
$$

where $q_{V}$-volumetric heat flux, $\lambda$-thermal conductivity.

For the fluid in bubbly or bubbly-slug flow the following assumptions were made, [9]:

1. Fluid flow in the minichannel is considered to be laminar and in steady state with constant mass flux.

2. Two phase mixture (liquid - vapour) in the minichannel can be characterised by the void fraction derived from the contribution of each phase in a mixture. The void fraction, constant at every cross section of the minichannel, is given by formula (1).

3 . Velocity vector of the fluid flow has only one non zero component $w=w(y)$ which is parallel to the heating surface of the minichannel. Assumed that velocity $w$ of the fluid varies linearly from $w=0$ close to internal walls of the minichannel to $w_{\max }$ along the axis of the minichannel, we get

$$
w(y)=\frac{w_{\max }}{\delta_{M}}\left(\delta_{M}-\left|2 y-\delta_{M}\right|\right)
$$

where $w_{\max }$ is equal to the doubled average fluid velocity.

4. Temperature of the fluid both at the minichannel inlet $\left(T_{\text {in }}\right)$ and outlet $\left(T_{\text {out }}\right)$ is known:

$$
\begin{gathered}
T_{f}(0, y)=T_{\text {in }} \text { for } \delta_{G}+\delta_{F} \leq y \leq \delta_{G}+\delta_{F}+\delta_{M} \\
T_{f}(L, y)=T_{\text {out }} \text { for } \delta_{G}+\delta_{F} \leq y \leq \delta_{G}+\delta_{F}+\delta_{M}
\end{gathered}
$$

5. Temperature of the fluid at the fluid-foil interface satisfies the condition:

$$
\begin{aligned}
& T_{f}\left(x, \delta_{G}+\delta_{F}\right)= \\
= & \left\{\begin{array}{ccc}
T_{F}\left(x, \delta_{G}+\delta_{F}\right), & \text { if } & T_{F}\left(x, \delta_{G}+\delta_{F}\right)<T_{\text {sat }}(x) \\
T_{\text {sat }}(x), & \text { if } & T_{F}\left(x, \delta_{G}+\delta_{F}\right) \geq T_{\text {sat }}(x)
\end{array}\right.
\end{aligned}
$$

where $T_{\text {sat }}(x)$ is the local saturation temperature dependent on the local pressure $p(x)$. The pressure changes linearly from the value it achieves at the inlet to the value at the outlet of the minichannel.

6. For bubbly and bubbly-slug flow we assume that the whole amount of heat generated by the heating foil enters the two phase mixture, proportionally to the void fraction $\varphi(x)$

$$
\begin{aligned}
& \lambda_{f} \frac{\partial T_{f}}{\partial y}=\lambda_{F}(1-\varphi(x)) \frac{\partial T_{F}}{\partial y} \\
& \text { for } y=\delta_{G}+\delta_{F}, 0 \leq x \leq L
\end{aligned}
$$

According to the above assumptions, energy conservation equation for the liquid phase has a following form

$$
\lambda_{f} \nabla^{2} T_{f}=w(y) c_{f} \rho_{f} \frac{\partial T_{f}}{\partial x}-\mu \Phi-w(y) \frac{d p}{d x}
$$

where $\Phi=\left(\frac{d w}{d y}\right)^{2}$ is a Rayleigh dissipation function, $c-$ specific heat, $\rho-$ density, $\mu-$ dynamic viscosity and $\frac{d p}{d x}$ is calculated from formula

$$
\frac{d p}{d x}=\mu \frac{\partial^{2} w}{\partial y^{2}}
$$

If temperature distribution and the heat flux at the boundary of the heating foil are known, the heat transfer coefficient $\alpha(x)$ at the foil-liquid interface can be calculated from the third kind condition; thus, the result is as follows

$$
\alpha(x)=\frac{\lambda_{F} \frac{\partial T_{F}\left(x, \delta_{G}+\delta_{F}\right)}{\partial y}}{T_{F}\left(x, \delta_{G}+\delta_{F}\right)-T_{a v e}(x)}
$$

where average temperature of the fluid

$$
T_{\text {ave }}(x)=\frac{1}{\delta_{M}} \int_{\delta_{G}+\delta_{F}}^{\delta_{G}+\delta_{F}+\delta_{M}} T_{f}(x, y) d y
$$

is assumed to be the reference temperature.

\section{Numerical method}

Two dimensional temperature field in the glass barrier, the heating foil and the boiling liquid was obtained by Trefftz method. Approximate solutions for (2) and (7) required Trefftz functions proper for Laplace equation. The description of computational procedure for solving heat equation in the glass barrier and the heating foil can be found in $[1,2]$. In order to approximate temperature distribution in the fluid, Trefftz functions for energy conserving equation (18) had to be generated. The obtained Trefftz functions $v_{k}(x, y)$ satisfy equation (18) in which the term

$$
\mu \Phi+w(y) \frac{d p}{d x}
$$

is omitted (as negligible) and velocity profile given by (13) is roof shaped (see [10]). The approximate solution to equation (18) consists of a linear combination of the derived Trefftz functions $v_{k}(x, y)$ and a particular solution $\widetilde{v}(x, y)$ to equation (18)

$$
T_{f}(x, y) \approx \sum_{k=0}^{K} a_{k} v_{k}(x, y)+\widetilde{v}(x, y)
$$

The unknown coefficients $a_{k}$ of the linear combination were determined by minimizing the error functional which described the mean square error with which function (23) satisfied the assumed conditions (14)-(17). The computational procedure is sequential. In the first 
step we get the solution in glass, next in the heating foil and finally in boiling fluid. The obtained approximate two dimensional distributions of temperature in the glass barrier $\left(T_{G}\right)$, in the heating foil $\left(T_{F}\right)$ and in the fluid $\left(T_{f}\right)$ satisfy equations (2), (7) and (18), respectively. The prescribed boundary conditions are satisfied only in variational sense. The problem of determining temperature in the glass barrier was a direct problem whereas $T_{F}$ and $T_{f}$ are solutions to the proper inverse problems in two neighbouring regions which, in terms of mathematical modelling, represent a solid and a fluid, i.e. two physical objects having thoroughly different physical properties.

\section{Results}

Numerical calculations were performed for experimental data and they concerned forced flow of the FC-72 through asymmetrically heated vertical minichannel. Calculations were conducted for setting \#17 with all parameters of the experiment given in figure 2 .
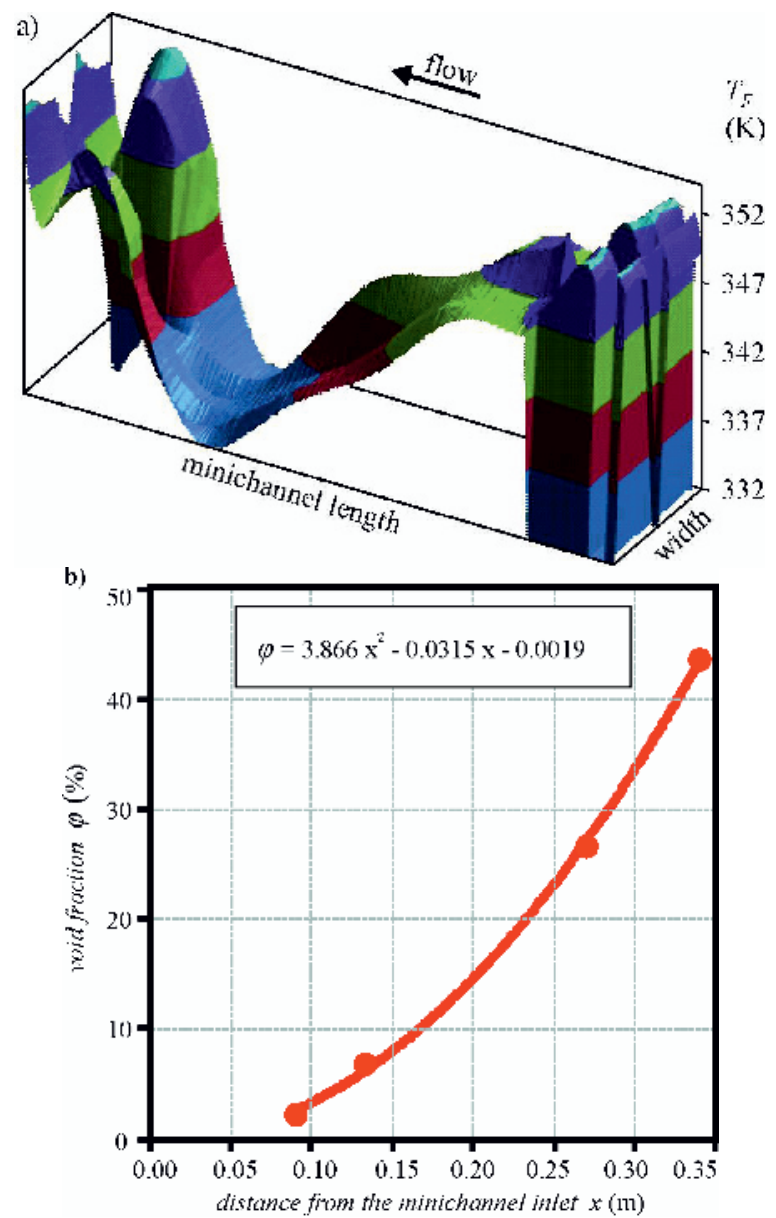

Figure 7. a) Two- dimensional temperature distribution at the foil-glass interface obtained with liquid crystal thermography, b) polynomial dependence of the void fraction dependence along the minichannel length for selected setting \#17.

In the first step of calculations the measurements obtained by the liquid crystal thermography were approximated with Trefftz functions in the manner described in [11] and presented in figure 7a. The void fraction described in detail in $\mathbf{2 . 3}$ was approximated with a quadratic function as shown in figure $7 \mathrm{~b}$. Two dimensional temperature distributions in glass, foil and fluid were determined at 9 surfaces parallel to the plane $\mathrm{XY}: z_{1}=16.57 \mathrm{~mm}, z_{2}=17.72 \mathrm{~mm}, z_{3}=18.86 \mathrm{~mm}$, $z_{4}=20.01 \mathrm{~mm}, z_{5}=21.15 \mathrm{~mm}, z_{6}=22.29 \mathrm{~mm}, z_{7}=23.44$ $\mathrm{mm}, z_{8}=24.58 \mathrm{~mm}, z_{9}=25.73 \mathrm{~mm}$, (see figure 6). Figure $8 \mathrm{a}$ presents the two-dimensional distribution of foil and fluid temperature calculated with the Trefftz method for surface $z_{5}=21.15 \mathrm{~mm}$. The temperature distribution of fluid, foil and saturation at the foil-fluid interface allows comparison of how the calculated temperature satisfies condition (16). The flow of the liquid in the channel is accompanied by a decrease in the pressure along the minichannel and thus there is a drop in the saturation temperature. These phenomena show dependences occurring in figure $8 b$, for analysed setting \#17. Figure 8a indicates the apparent effect of the assumed velocity profile (13) on the fluid temperature distribution.

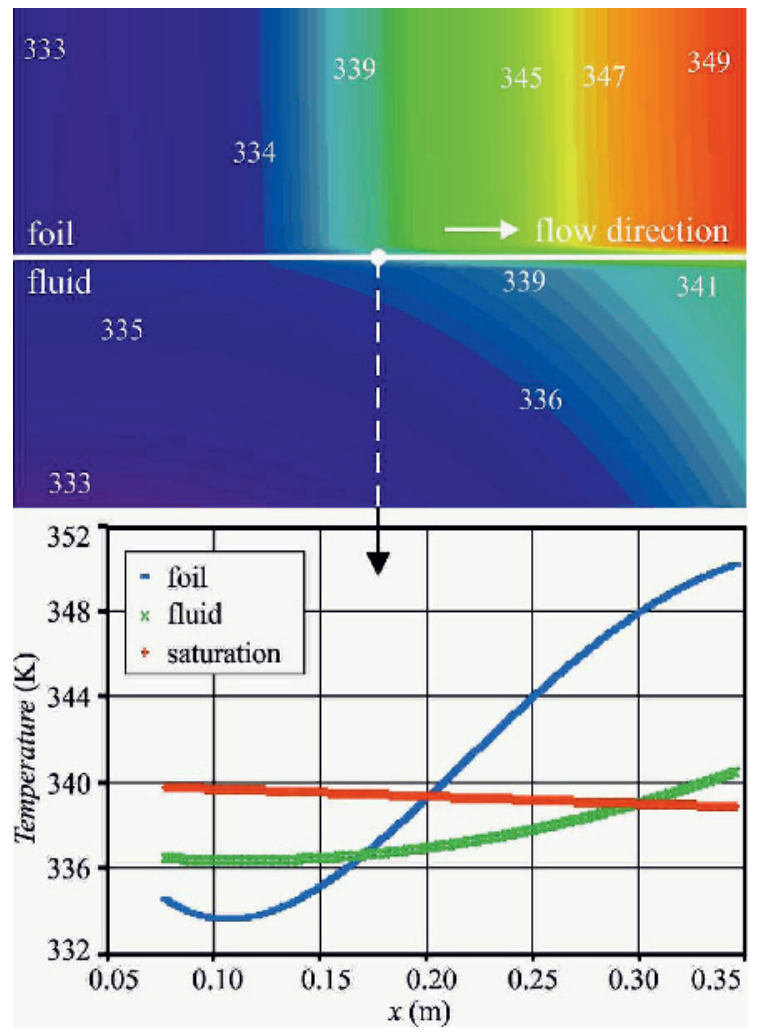

Figure 8. Data for selected setting \#17: a) two-dimensional distribution of foil and liquid in the minichannel, calculated by Trefftz method, b) temperature of the foil, temperature of the fluid and the saturation temperature as a function of the distance from the minichannel inlet.

The known fluid temperature distribution allowed calculating heat transfer coefficient at the foil-glass contact points from the condition (20). Figure 9a shows the heat transfer coefficient as a function of the minichannel depth, calculated from all surfaces $z_{i}, i=1,2 \ldots, 9$ for setting \#17. The local heat transfer coefficient for a section of the area in 3D arrangement is shown in figure $9 \mathrm{~b}$. Locally determined heat transfer 
coefficient values are unknown in some areas due to the lack of information on the surface temperature (data outside the active spectrum of applied liquid crystals). The other reason why heat transfer coefficient cannot be obtained in some areas is of numerical nature. Accurate solution requires a big number of Trefftz functions but on the other hand, when too many Trefftz functions are used, the solution may suffer from unbounded oscillations. Analytical differentiation of the solution which is necessary for computation of the heat transfer coefficient, usually amplifies the errors and the final results may be unreliable.

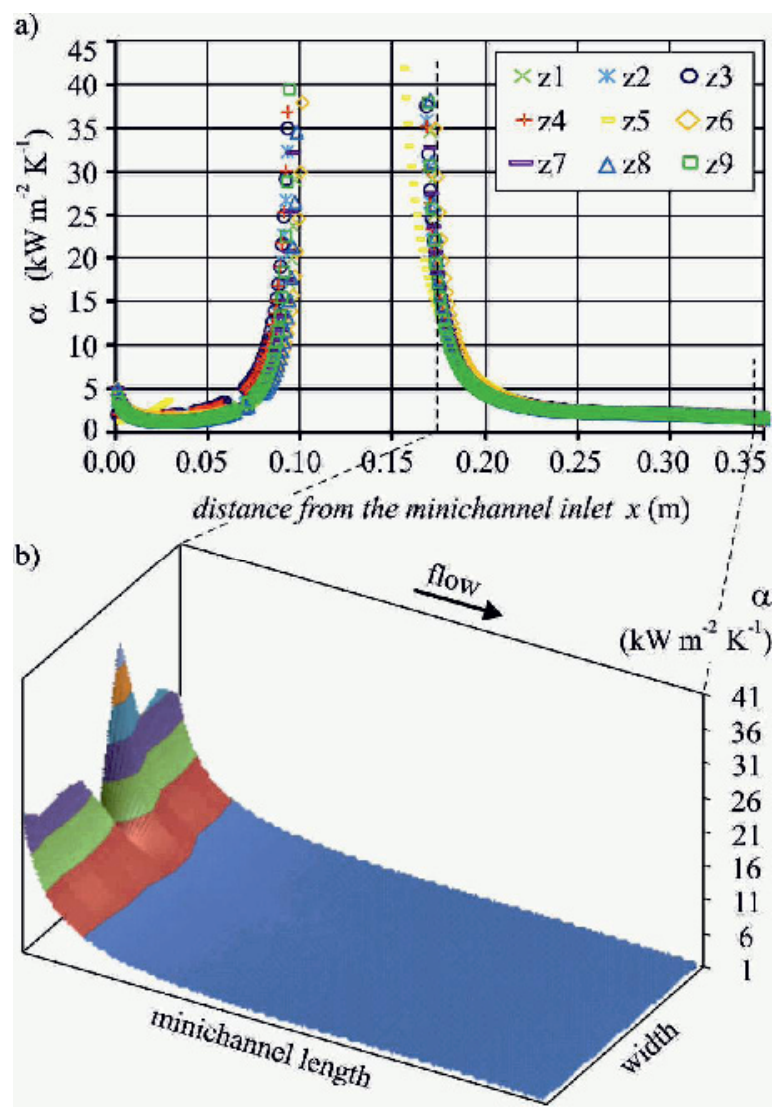

Figure 9. Heat transfer coefficient, determined for:

a) all surfaces $z_{i}, i=1,2 \ldots, 9$, as a function of the minichannel length, b) marked section of the area in $3 \mathrm{D}$ arrangement $3 \mathrm{D}$; data for setting \#17.

When the heat flux supplied to the heating foil increases, a hue sequence in the upper part of images appears, in accordance with the spectrum sequence (see figure 2a). This occurs when transition boiling and then developed nucleate boiling is in progress in the minichannel and the heating surface becomes superheated. It is accompanied by the pressure increase in the channel, flow fluctuations, a sharp increase in the liquid temperature in the flow core and flow resistance fluctuations. Enlarging vapour bubbles that combine into larger agglomerates are observed in the images of the flow structures [4]. In the case of the developed boiling the heat transfer coefficient starts sharply to decrease (figure 9b). For higher shares of the vapour phase in the two-phase mixture during developed boiling, heat transfer coefficient values will decrease in a milder way. Adjustment calculus, applied to measurement data in a way described in [11] smoothed the measurements and reduced the measurement errors. When the heat transfer coefficient $\alpha$ is defined by equation (20), then it contains error $\Delta \alpha$ which can be calculated from the formula

$$
\begin{aligned}
& \Delta \alpha=\left[\left(\frac{\partial \alpha}{\partial T_{F}} \cdot \Delta T_{F}\right)^{2}+\left(\frac{\partial \alpha}{\partial T_{a v e}} \cdot \Delta T_{\text {ave }}\right)^{2}+\right. \\
& \left.+\left(\frac{\partial \alpha}{\partial \lambda_{F}} \cdot \Delta \lambda_{F}\right)^{2}+\left(\frac{\partial \alpha}{\partial \frac{\partial T_{F}}{\partial y}} \cdot \Delta \frac{\partial T_{F}}{\partial y}\right)^{2}\right]^{1 / 2}
\end{aligned}
$$

where:

$\Delta \lambda_{F}-$ accuracy of the heat conductivity determination, $\Delta \lambda_{F}=0.1(\mathrm{~W} / \mathrm{mK})[1]$,

$\Delta T_{F}$ - accuracy of the foil temperature approximation (since the foil is very thin, we can assume that $\Delta T_{F}$ is equal to the error of the temperature measurement [1], $\Delta \frac{\partial T_{F}}{\partial y}=\left|\frac{\partial^{2} T_{F}}{\partial y \partial x} \Delta x\right|$, where $\Delta x$ equals four times the pixel dimension: $\Delta x=7.4 \cdot 10^{-4} \mathrm{~m}$ as the measured temperature is an average over the temperature at the point and its four surrounding neighbours [1],

$\Delta T_{\text {ave }}$ - reference temperature measurement error was calculated with formula

$$
\begin{aligned}
& \Delta T_{\text {ave }}= \frac{1}{\delta_{M}}\left[\left(\int_{\delta_{G}+\delta_{F}}^{\delta_{G}+\delta_{F}+\delta_{M}} \frac{\partial T_{f}}{\partial x} d y \Delta x\right)^{2}+\right. \\
&\left.+\left(\int_{\sigma_{G}+\delta_{F}}^{\delta_{G}+\delta_{F}+\delta_{M}} \frac{\partial T_{f}}{\partial y} d y \Delta y\right)^{2}\right]
\end{aligned}
$$

where $\Delta y=\Delta x$. Average relative error of the heat transfer coefficient, $\Delta \alpha / \alpha$, calculated for setting $\# 17$ is equal to $34.6 \%$. After application of adjustment calculus it decreases by 2.5 times, to $13.6 \%$. To understand why the original error of $\alpha$ turned to be so large $(>30 \%)$, one should note that computation of $\alpha$ required solving three heat conduction problems connected with one another. The first was a direct problem (in the glass), the two remaining were inverse problems (in the foil and in the fluid).

\section{Conclusions}

The paper presents numerical modelling of temperature fields in flow boiling in a vertical minichannel with an enhanced heating surface. Two dimensional temperature fields in the glass pane, the heating foil and the fluid in flow were determined by Trefftz method. The obtained numerical results show the high compliance with physical 
assumptions of the model and they have satisfactory accuracy. Boiling incipience makes the heat transfer coefficient increase very rapidly. As the heat flux supplied to heating foil grows, the contribution of gasphase increases which results in heat transfer coefficient drop. Application of adjustment calculus for approximation of measurement data allowed to smooth the measurements and reduce their errors. Also, the is an improved estimation of the heat transfer coefficient (adjustment calculus diminished the error of this estimation).

\section{References}

1. S. Hozejowska, M. Piasecka, M.E. Poniewski, Int. J. Therm. Sci. 48 1049-1059 (2009)

2. M. Piasecka, S. Hożejowska, M.E. Poniewski, Int.J. Heat Fluid Flow 25 159-172 (2004)

3. M. Piasecka M., Maciejewska B., Exp. Thermal Fluid Sci. 38 19-32 (2012)

4. M. Piasecka, Int. J. Heat and Mass Transf. 66 472488 (2013)

5. M. Piasecka, Exp. Heat Transfer, DOI: 10.1080/08916152.2013.782374 (2013)

6. M. Piasecka, B. Maciejewska, Exp. Thermal Fluid Sci. 44 23-33 (2013)

7. M. Piasecka, Heat Mass Transf. 49 261-271 (2013)

8. M. Piasecka, Metrology and Meas. Sys. XX, 205216 (2013)

9. S. Hożejowska, R. Kaniowski, M.E. Poniewski, Int. J. Numer. Methods Heat Fluid Flow, (to be published)

10. S.Hożejowska, M. Piasecka, L. Hożejowski, EPS Web of Conf. 4501040 (2013)

11. K. Grysa, S. Hożejowska, B. Maciejewska, JTAM, 50, 1087-1096 (2012) 